\title{
THE DEVELOPMENT OF STATISTICAL LITERACY ASSESSMENT TOOL FOR SENIOR STUDENTS IN ELEMENTARY SCHOOLS
}

\author{
Chien-Ming Cheng \\ National Academy for Educational Research/Research Center for Testing and Assessment (Taiwan)
}

\begin{abstract}
The most critical capabilities of the twenty-first century are: learning and innovation ability, information, media and technology literacy, work and life skills. Key competencies in information literacy included data interpretation and the prediction of possibility, which has a critical impact for the decision of problem solving. However, analysis, interpretation of data, prediction and judgment are statistical literacy. To cultivate the ability of data analysis, interpretation, and the prediction and judgment of event probably occurring is the prior knowledge of statistical literacy in elementary school. Therefore, this study used data and chance as item content to compile a set of crossing grade assessment with reliability and validity. The assessment and its parallel norm tests suit to evaluate the students' statistical literacy development in the fifth and sixth grade.

The research results are as follows: 1. This study applied the Rasch model to explore the validity of the "Statistical literacy assessment tool". The results found that most of the items were goodness of fit.

2. This study, by concurrent estimating the difficulty of all the items and the ability of the students, showed that the ability of the students of different grades was significantly different, and the higher the grade, the higher the ability of the students.

3. This research is the parallel design of the test items. It can be used as a longitudinal study assessment tool to explore the statistical literacy of students in the fifth and sixth grades, and can reduce the threat of validity for repeating the test.
\end{abstract}

Keywords: Statistical literacy, assessment tool, elementary school.

\section{Introduction}

a. The Partnership for 21st Century Skills (P21) believes that the key capabilities most needed in the 21 st century are: the ability to learn and innovate, information literacy, media and technology literacy, work and life skills (Liu, 2012).

b. No matter what occupation, correctly understanding and presenting of chart information, there are already existing every corner of life and workplace.

c. There are only a few articles and project reports on the development of students' statistical literacy concepts, indicators and tests in Taiwan.

d. The survey results of PISA, TIMSS and TASA found that the statistical literacy scores of Taiwan's primary and secondary schools is relatively weak compared to the whole (Lin, Ren, Li, Lin, Chang, Cao, Yang, 2014; PISA in Taiwan, 2014).

\section{Objectives}

Therefore, the research is to compile a set of test and parallel test for assessing students' statistical literacy-data and chance ability and understanding the development of students' data and chance ability in the fifth and sixth grades. It is also an important tool for assessing curriculum development, teacher instruction, and students' data and chance ability. The followings are the research's objectives:

a. Administering the items of the test and all the parallel tests in order to establish a norm test and confirm the reliability and validity.

b. Administering the criterion-related test - mathematical achievement test and analyzing the validity of the criterion.

c. Analysis of the overall status of the sample students' data and chance ability.

d. Analysis of data and chance ability, and other sub-projects - the relationship between mathematical vocabulary, mathematical writing and computing ability in order to understand the important factors related to the ability of data and chance.

\section{Methods}

\subsection{The test development process}

a. Establishing statistical literacy connotation 
b. Establishing a statistical literacy assessment framework

c. Setting the item type and length

d. Designing and revising procedures

e. Test compiling and data collection

3.2 Rasch model analyzing "statistical literacy test"

3.3 The research objects

For the fifth and sixth grade students, the sample statistics are as follows:

Table 1. Pre-test statistics description for the number of people in each grade.

\begin{tabular}{cccc}
\hline grade & five & six & total \\
\hline number & 514 & 523 & 1037 \\
\hline
\end{tabular}

Table 2. Formal test sampling description table.

\begin{tabular}{lcccc}
\hline grade & \multicolumn{2}{c}{ five } & \multicolumn{2}{c}{ six } \\
\hline area & number & proportion & number & proportion \\
\hline north 1 & 20 & 0.04 & 137 & 0.27 \\
\hline north 2 & 105 & 0.22 & 85 & 0.16 \\
\hline center & 209 & 0.44 & 80 & 0.16 \\
\hline south & 121 & 0.25 & 178 & 0.34 \\
\hline east+distance & 23 & 0.05 & 36 & 0.07 \\
\hline 合計 & 478 & 1.00 & 516 & 1.00 \\
\hline
\end{tabular}

\subsection{Data analysis}

3.2.1. Rasch model. Since the test includes binary and multivariate scoring items, the Rasch partial credit model (Master, 1982) is adopted.

3.2.2. Validity analysis. The validity certificate is established from the two aspects of the test content and the internal structure.

3.2.3. Reliability analysis. This study used subject separation reliability and EAP reliability.

\section{Results}

\subsection{Fifth and sixth grade assessment framework}

Table 3.

\begin{tabular}{lcccc}
\hline \multicolumn{1}{c}{ content } & Concept understanding & Procedure executing & Solving and reasoning & total \\
\hline Data collation and presentation & 3 & 2 & 0 & $5(23.8 \%)$ \\
\hline Data reading and interpretation & 2 & 4 & 4 & $10(47.6 \%)$ \\
\hline possibility & 3 & 1 & 2 & $6(28.6 \%)$ \\
\hline total & $8(38.1 \%)$ & $7(33.3 \%)$ & $6(28.6 \%)$ & $21(100 \%)$ \\
\hline
\end{tabular}

\subsection{Validity evaluation results}

4.2.1. Construct validity. Rasch model goodness of fit item goodness of fit except for the 3 questions in Volume 2, the MNSQ of all the other items fell between $1 \pm 0.3$.

Table 4.

\begin{tabular}{ccccc}
\hline \multicolumn{2}{c}{ Volume Ave. b } & Area b & MNSQ & \# outlier of MNSQ \\
\hline 1 & -0.22 & $-2.04 \sim 1.00$ & $0.74 \sim 1.17$ & 0 \\
\hline 2 & -0.35 & $-1.98 \sim 1.30$ & $0.65 \sim 1.33$ & 3 \\
\hline 3 & -0.10 & $-2.00 \sim 1.20$ & $0.79 \sim 1.21$ & 0 \\
\hline
\end{tabular}

Estimated difficulty of each test in each year

Using the good anchor items' parameters which were set up in the previous pre-test, the answers of all the students in the two grades are concurrently estimated, so that the student's ability and the test difficulty can be estimated under the same scale. The average difficulty of the test questions is -.22 , which means that for the whole student, the test items are median and tend to easy. 


\section{Vertical scale and item calibration}

The researcher used one-way ANOVA to compare differences in data and chance abilities between students in the two grades. The analysis showed significantly different between two years, sixth grade $(\mathrm{M}=.51, \mathrm{SD}=.79)$ significantly higher than the fifth grade $(\mathrm{M}=.23, \mathrm{SD}=.70)$.

Expert validity

The expert validity adopted in this research, in the assessment framework part, is through expert consultation meeting. There are 5 experts and scholars, including 2 mathematics education, 1 special education, 1 mathematics cognition and learning problem diagnosis, 1 psychometrician to confirm and build the assessment framework. The validity of the test items is confirmed after discussion and revision based on 6 elementary teachers with more than five years of teaching experience, and 1 psychometrician doctor.

\subsection{Reliability analysis result}

Table 5. Subject separation and EAP reliability table.

\begin{tabular}{|c|c|c|c|}
\hline $\mathrm{rad}$ & iter & tsep & rell \\
\hline 5 & 103 & 0.98 & 0.71 \\
\hline 6 & 103 & 0.98 & 0.75 \\
\hline
\end{tabular}

\subsection{Simultaneously measure the validity of the data and possibility ability, and analyze the criterion-related validity}

Table 6.

\begin{tabular}{llcc}
\hline \multirow{2}{*}{ Math vocabulary } & \multicolumn{3}{c}{5 grade 6 grade } \\
\cline { 2 - 4 } & Pearson correlation & $.57^{* *}$ & $.69^{* *}$ \\
\hline \multirow{2}{*}{ Math words } & Pearson correlation & $.60^{* *}$ & $.72^{* *}$ \\
\cline { 2 - 4 } & Number & 193 & 217 \\
\hline \multirow{2}{*}{ Math calculation } & Pearson correlation & $.49^{* *}$ & $.56^{* *}$ \\
\cline { 2 - 4 } & Number & 184 & 189 \\
\hline \multirow{2}{*}{ Statistical literacy } & Pearson correlation & 1 & 1 \\
\cline { 2 - 4 } & Number & 478 & 509 \\
\hline \multirow{2}{*}{ Math achievement } & Pearson correlation & $.71^{* *}$ & $.68^{* *}$ \\
\cline { 2 - 4 } Number & 185 & 205 \\
\hline **. p<.01 & &
\end{tabular}

\section{Discussion} findings:

Although the overall reliability and validity are good for the norm test tool. There are still some

Although the parallel tests have been pre-tested and analyzed to select good items for assembling items, and take the spiral test during the test. However, the post-test analysis still finds that it will be affected by the samples, resulting in seemingly parallel items whose parameters are still different. In addition, the average difficulty of the whole test is still different. Because of the budget constraints, the samples to be administered are still limited. If a larger samples and tests can be carried out, the results of parallel tests may be better.

The reliability analysis of fifth grade is .71 , which may be related to the development of the students, and because the teacher is entrusted to help the test. There is only a description of the paper; there is no training and explanation for the supervision, so the reliability is slightly lower.

\section{References}

Liu, X. H. (translated) (2012). The future of education - the key capabilities we need. (Original author Trilling, B. \& Fadel, C. $21^{\text {st }}$ Century Skills: Learning for Life in Our Times). Wild Goose Culture: Taipei City.

Lin, C. Y., Ren, Z. H., Li, Z. D., Lin, B. Z., Zhang, M. Y., Cao, B. S., \& Yang, W. J. (2014). The Trends in international Mathematics and Science Study 2011. Taipei City: Normal University Science and Education Center.

Masters, G. N. (1982). A Rasch model for partial credit scoring. Psychometrika, 47, 149-174.
PISA in Taiwan (2014). Taiwan
PISA2012 streamlined
report.
Retried from http://pisa.nutn.edu.tw/download_tw.htm 